\title{
Women and men have similar amounts of liver and intra-abdominal fat, despite more subcutaneous fat in women: implications for sex differences in markers of cardiovascular risk
}

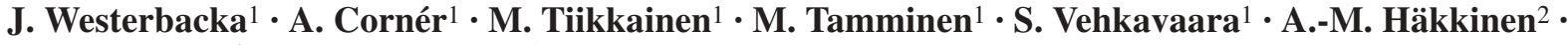 \\ J. Fredriksson ${ }^{3} \cdot$ H. Yki-Järvinen ${ }^{1}$ \\ ${ }^{1}$ Department of Medicine, Division of Diabetes, University of Helsinki, Helsinki, Finland \\ 2 Department of Oncology, University of Helsinki, Finland \\ ${ }^{3}$ Department of Endocrinology, Wallenberg Laboratory, Malmö University Hospital, Malmö, Sweden
}

\section{Abstract}

Aims/hypothesis. Fat accumulation in the liver has been shown to be closely correlated with hepatic insulin resistance and features of insulin resistance, also independently of body weight. It remains to be established how fat in the liver correlates with that in other depots, and whether any association differs between men and women.

Methods. Liver fat (assessed using proton spectroscopy), intra-abdominal and subcutaneous fat (measured using magnetic resonance imaging) and markers of insulin resistance, including serum adiponectin, were determined in 132 non-diabetic subjects: 66 men (age $41 \pm 1$ years) and 66 women (age $42 \pm 1$ years).

Results. Although the women had almost twice as much subcutaneous fat as the men $(5045 \pm 207$ vs $\left.2610 \pm 144 \mathrm{~cm}^{3}, p<0.0001\right)$, amounts of intra-abdominal fat $\left(1305 \pm 80\right.$ vs $1552 \pm 111 \mathrm{~cm}^{3}$, NS) and liver fat $(6.7 \pm 0.8$ vs $8.9 \pm 1.2 \%, \mathrm{NS})$ were similar. In this study, no sex differences were observed with respect to serum insulin, adiponectin, triglyceride and HDL cho- lesterol concentrations. Of all measures of body composition, liver fat was best correlated with serum insulin $(r=0.58, p<0.001)$, with no difference observed between men and women. Serum adiponectin was inversely correlated with liver fat content $(r=-0.21$, $p<0.05)$. Multiple linear regression analysis revealed that intra-abdominal fat was significantly associated with liver fat, independently of serum adiponectin and subcutaneous fat. Liver fat, but not intra-abdominal fat, significantly explained the variation in serum insulin concentrations.

Conclusions/interpretation. Intra-abdominal fat is independently associated with liver fat, whereas subcutaneous fat is not. Liver fat, but not intra-abdominal fat, is independently associated with serum insulin. Men and women with similar amounts of intra-abdominal and liver fat do not exhibit sex differences in markers of insulin resistance (serum insulin, triglycerides, HDL cholesterol and adiponectin).

Keywords Glucose $\cdot$ NEFA $\cdot$ Non-alcoholic fatty liver disease $\cdot$ Visceral fat
Received: 27 January 2004 / Accepted: 28 April 2004

Published online: 28 July 2004

(C) Springer-Verlag 2004

J. Westerbacka $(\bowtie)$

Department of Medicine, Division of Diabetes,

University of Helsinki, P.O. Box 340, 00029 HUCH,

Helsinki, Finland

E-mail: jukka.westerbacka@helsinki.fi

Tel.: +358-9-47171885, Fax: +358-9-47175585

Abbreviations: ALT, alanine aminotransferase - AST, aspartate aminotransferase · GGT, gamma glutamyl transferase $\cdot$ MRI, magnetic resonance imaging - NAFLD, non-alcoholic fatty liver disease $\cdot$ SNP, single nucleotide polymorphism

\section{Introduction}

Non-alcoholic fatty liver disease (NAFLD) is the most common cause of elevated liver enzyme concentrations, and is currently the third leading cause of liver cirrhosis [1]. In an analysis of 15676 individuals in the US, the prevalence of elevated liver enzymes was $7.9 \%$. Of these, only $31 \%$ were explained by excess alcohol consumption, viral hepatitis or haemochromatosis [1]. In the remaining $69 \%$, various features of insulin resistance (overall and abdominal obesity, hypertriglyceridaemia, hyperinsulinaemia and low HDL cholesterol) were strongly associated with an other- 
wise unexplained elevation of liver enzymes. Several other recent studies have also found NAFLD to be strongly associated with insulin resistance in both obese [2] and non-obese [3] subjects.

Upper body obesity, independently of relative body weight, is associated with various features of insulin resistance $[4,5,6]$ and a high risk of developing Type 2 diabetes [7, 8] and cardiovascular disease [9]. It is also related to an increased amount of intra-abdominal fat, but whether this depot is an innocent bystander or a cause of insulin resistance is controversial [10]. The possibility that intra-abdominal fat may not be the most proximal correlate of insulin resistance is supported by studies showing that severe insulin resistance can be observed in the absence of intra-abdominal fat in both rodent and human models. Patients with congenital generalised lipoatrophy have severe insulin resistance, but lack both subcutaneous and intra-abdominal fat [11]. Aricid extension-leucine zipper lipoatrophic mice are severely insulin resistant, but have neither mesenteric nor omental fat [12]. Both lipoatrophic conditions are, however, characterised by increased fat accumulation in insulin-sensitive tissues, especially skeletal muscle and the liver. In the aricid extension-leucine zipper mouse, subcutaneous fat transplantation reverses insulin resistance and normalises liver and muscle fat content [13]. These data suggest that fat accumulation in the liver or muscle may be more closely related to features of insulin resistance than the amount of intra-abdominal fat. Consistent with this idea, it has recently been demonstrated that increased alanine aminotransferase (ALT) activity predicts the development of Type 2 diabetes, independently of body fat [14]. Also, several recent studies that included small numbers of subjects have shown that liver fat is associated with features of insulin resistance independently of BMI in non-obese lipodystophic [15] and normal [16] men and obese women [17]. However, these studies, which only investigated a narrow range of BMIs, did not assess the relationships between liver fat content and the size of other fat depots, particularly intra-abdominal fat, or whether such relationships are sexually dimorphic. It is also unclear whether circulating levels of adiponectin (an adipocyte-derived hormone associated with insulin resistance) $[18,19]$ or genetic variation at position 276 of the adiponectin gene $[20,21]$ are associated with liver fat content.

The present study aimed to determine how liver fat content (measured using proton spectroscopy) is related to the size of other fat depots (measured using magnetic resonance imaging $[\mathrm{MRI}]$ ) and features of insulin resistance in a relatively large number of nondiabetic men and women. The results show that, of all measures of body fat, liver fat is best correlated with features of insulin resistance, and that for a given amount of intra-abdominal and liver fat, women may possess up to twice as much subcutaneous fat as men.

\section{Subjects and methods}

Subjects and study design. A total of 132 non-diabetic, apparently healthy Caucasian subjects were recruited from occupational health services based on the following inclusion criteria: (i) aged 18 to 60 years; (ii) no known acute or chronic disease based on history and physical examination and standard laboratory tests (blood counts, serum creatinine, thyroid-stimulating hormone, electrolyte concentrations and ECG). Exclusion criteria included treatment with drugs that may alter glucose tolerance, pregnancy or clinical or biochemical evidence of any significant disease other than obesity. Elevated liver enzymes (serum ALT, aspartate aminotransferase [AST] and gamma glutamyl transferase [GGT]) were not an exclusion criterion. However, subjects with serological evidence of hepatitis B or C, autoimmune hepatitis, clinical signs or symptoms of inborn errors of metabolism or a history of use of toxins or drugs associated with liver steatosis were excluded, as were subjects consuming more than $20 \mathrm{~g}$ of alcohol per day. If eligible, the subjects were studied after an overnight fast to assess body composition and features of insulin resistance, as detailed below. Data from 30 men who had been previously characterised [16] were included in the present analysis.

The nature and potential risks of the study were explained to all subjects prior to obtaining their written informed consent. The protocol was approved by the ethics committee of the Helsinki University Central Hospital.

Measurement of liver fat content. Localised single voxel $\left(2 \times 2 \times 2 \mathrm{~cm}^{3}\right)$ proton spectra were acquired using a $1.5-\mathrm{T}$ whole-body system (Siemens Magnetom Vision, Erlangen, Germany), which consisted of a combination of whole-body and loop surface coils for radiofrequency transmitting and signal receiving. T1-weighted high-resolution MRI scans were used for localisation of the voxel of interest within the right lobe of the liver. Magnetic resonance spectroscopy measurements of the liver fat were performed in the middle of the right lobe of the liver at a location that was individually determined for each subject; vascular structures and subcutaneous fat tissue were avoided when selecting the voxel. Subjects lay on their stomachs on the surface coil, which was embedded in a mattress in order to minimise abdominal movement due to breathing. The single voxel spectra were recorded using the stimulated-echo acquisition mode sequence, with an echo time of $20 \mathrm{~ms}$, a repetition time of $3000 \mathrm{~ms}$, a mixing time of $30 \mathrm{~ms}, 1024$ data points over $1000 \mathrm{kHz}$ spectral width with 32 averages. Water-suppressed spectra with 128 averages were also recorded to detect weak lipid signals. A short echo time and long repetition time was chosen to ensure a fully relaxed water signal, which was used as an internal standard. Chemical shifts were measured relative to water at $4.80 \mathrm{ppm}$. The methylene signal, which represents intracellular triglyceride, was measured at $1.4 \mathrm{ppm}$. Signal intensities were quantified by using an analysis program, VAPRO-MRUI (http://www.mrui. uab.es/mrui/). Spectroscopic intracellular triglyceride content (liver fat) was expressed as:

methylene $/($ water + methylene $)$ signal area ratio $\times 100$

This measurement has been validated against histologically determined lipid content [22] and against estimates of fatty degeneration or infiltration by X-ray computer-assisted tomography [23]. All spectra were analysed by a physicist (A.-M. Häkkinen) who was unaware of any of the clinical data. The reproducibility of repeated measurements of liver fat in non-diabetic subjects studied on two occasions in our laboratory is $11 \%$ [15]. 
Table 1. Characteristics of the study subjects

\begin{tabular}{|c|c|c|c|}
\hline & Women $(n=66)$ & Men $(n=66)$ & $p$ value \\
\hline Age (years) & $42 \pm 1$ & $41 \pm 1$ & NS \\
\hline Body weight $(\mathrm{kg})$ & $83 \pm 2$ & $85 \pm 2$ & NS \\
\hline \multicolumn{4}{|c|}{ Overall and subcutaneous adiposity } \\
\hline Body mass index $\left(\mathrm{kg} / \mathrm{m}^{2}\right)$ & $30.1 \pm 0.5$ & $26.5 \pm 0.5$ & $p<0.0001$ \\
\hline Subcutaneous fat $\left(\mathrm{cm}^{3}\right)$ & $5045 \pm 207$ & $2610 \pm 144$ & $p<0.0001$ \\
\hline Whole body fat (\%) & $35 \pm 1$ & $21 \pm 1$ & $p<0.0001$ \\
\hline Fat mass (kg) & $30 \pm 1$ & $18 \pm 1$ & $p<0.0001$ \\
\hline \multicolumn{4}{|c|}{ Intra-abdominal adiposity and liver fat } \\
\hline Liver fat $(\%)$ & $6.7 \pm 0.8$ & $8.9 \pm 1.2$ & NS \\
\hline Intra-abdominal fat $\left(\mathrm{cm}^{3}\right)$ & $1305 \pm 80$ & $1552 \pm 111$ & NS \\
\hline Waist-to-hip ratio & $0.99 \pm 0.02$ & $0.97 \pm 0.01$ & NS \\
\hline \multicolumn{4}{|l|}{ Features of insulin resistance } \\
\hline Insulin $(\mathrm{mU} / \mathrm{l})^{\mathrm{a}}$ & $10 \pm 1$ & $9 \pm 1$ & NS \\
\hline C-peptide $(\mathrm{nmol} / \mathrm{l})^{\mathrm{a}}$ & $0.8 \pm 0.1$ & $0.8 \pm 0.1$ & NS \\
\hline LDL cholesterol $(\mathrm{mmol} / \mathrm{l})^{\mathrm{a}}$ & $3.1 \pm 0.1$ & $3.1 \pm 0.1$ & NS \\
\hline Triglycerides $(\mathrm{mmol} / \mathrm{l})^{\mathrm{a}}$ & $1.5 \pm 0.1$ & $1.7 \pm 0.2$ & NS \\
\hline HDL cholesterol $(\mathrm{mmol} / \mathrm{l})^{\mathrm{a}}$ & $1.4 \pm 0.1$ & $1.3 \pm 0.1$ & NS \\
\hline Adiponectin $(\mathrm{mg} / \mathrm{l})^{\mathrm{a}}$ & $11 \pm 1$ & $11 \pm 1$ & NS \\
\hline $\operatorname{ALT}(\mathrm{U} / 1)^{\mathrm{a}}$ & $35 \pm 4$ & $53 \pm 8$ & $p<0.05$ \\
\hline $\operatorname{AST}(U / 1)^{a}$ & $32 \pm 3$ & $35 \pm 3$ & NS \\
\hline
\end{tabular}

Values are means \pm SEM. a Serum fasting level. ALT, alanine aminotransferase; AST, aspartate aminotransferase

Assessment of intra-abdominal and subcutaneous fat. Intra-abdominal and subcutaneous fat volumes were determined using MRI. A series of T1-weighted trans-axial scans were acquired from a region extending from $8 \mathrm{~cm}$ above to $8 \mathrm{~cm}$ below the 4 th and 5th lumbar interspace (16 slices, field of view $375 \times 500 \mathrm{~mm}^{2}$, slice thickness $10 \mathrm{~mm}$, breath-hold repetition time $138.9 \mathrm{~ms}$, echo time $4.1 \mathrm{~ms}$ ). Intra-abdominal and subcutaneous fat areas were measured using an image analysis program (Alice 3.0, Parexel, Waltham, Mass., USA). A histogram of pixel intensity in the intra-abdominal region was displayed, and the intensity corresponding to the nadir between the lean and fat peaks was used as a cut-off point. Intra-abdominal adipose tissue was defined as the area of pixels in the intra-abdominal region above this cut-off point. For calculation of subcutaneous adipose tissue area, a region of interest was first manually drawn at the demarcation of subcutaneous adipose tissue and intra-abdominal adipose tissue, as previously described [23]. The reproducibility of repeated measurements of subcutaneous and intra-abdominal fat is $3 \%$ and $5 \%$ respectively [15].

Measurement of other parameters. Blood samples were taken after an overnight fast for measurement of plasma glucose, serum insulin and $\mathrm{C}$-peptide, $\mathrm{HbA}_{1} \mathrm{c}$, liver enzymes, serum triglyceride and total and HDL cholesterol concentrations, and for extraction of genomic DNA. Percentage body fat was determined using bioelectrical impedance analysis (BioElectrical Impedance Analyzer System, model number BIA-101A, RJL Systems, Detroit, Mich., USA) [24]. Waist circumference was measured midway between spina iliaca superior and the lower rib margin, and hip circumference at the level of the greater trochanters [25].

Analytical procedures. Plasma glucose concentrations were measured in duplicate using the glucose oxidase method and a Beckman Glucose Analyzer II (Beckman Instruments,
Fullerton, Calif., USA) [26]. Serum-free insulin concentrations were measured using the Auto-DELFIA kit (Wallac, Turku, Finland). C-peptide concentration was determined by RIA [27]. $\mathrm{HbA}_{1} \mathrm{c}$ was measured by HPLC using the fully automated Glycosylated Hemoglobin Analyzer System (BioRad, Richmond, Calif., USA) [28]. Serum total cholesterol, HDL cholesterol and triglyceride concentrations were measured with the appropriate enzymatic kits from Roche Diagnostics using an autoanalyser (Roche Diagnostics Hitachi, Hitachi Ltd., Tokyo, Japan). LDL cholesterol concentration was calculated using the Friedewald formula [29]. Serum ALT, AST and GGT activities were determined as recommended by the European Committee for Clinical Laboratory Standards. Serum adiponectin concentrations were measured using an ELISA kit (B-Bridge International, San Jose, Calif., USA).

Genotyping the single nucleotide polymorphism (SNP) at position 276 of the adiponectin gene. The APM1 SNP276 G $\rightarrow T$ polymorphism was genotyped in 112 subjects using allelic discrimination in the ABI PRISM 7900 Sequence Detection System (Applied Biosystems, Foster City, Calif., USA) according to the manufacturer's instructions in a volume of $5 \mu$ l. Primers (TTCATCACAGAC CTCCTACACTGA and TCCCTGTGTCTAGGCCTTAGTTAAT) and probes (ACTATATGAAGGCATTCAT and AAACTATATGAAGTCATTCAT) were ordered as Assay-by-Design (Applied Biosystems).

Statistical analyses. Non-normally distributed data were used after logarithmic transformation. The unpaired Student's $t$ test was used to compare mean values between men and women. The runs test was used to determine whether a non-linear model was required to relate measures of body composition and insulin resistance or measures of liver fat [30]. These analyses were performed separately for men and women. Analysis of covariance was used to compare slopes and intercepts of regression lines for men and women. If neither the slopes nor the 

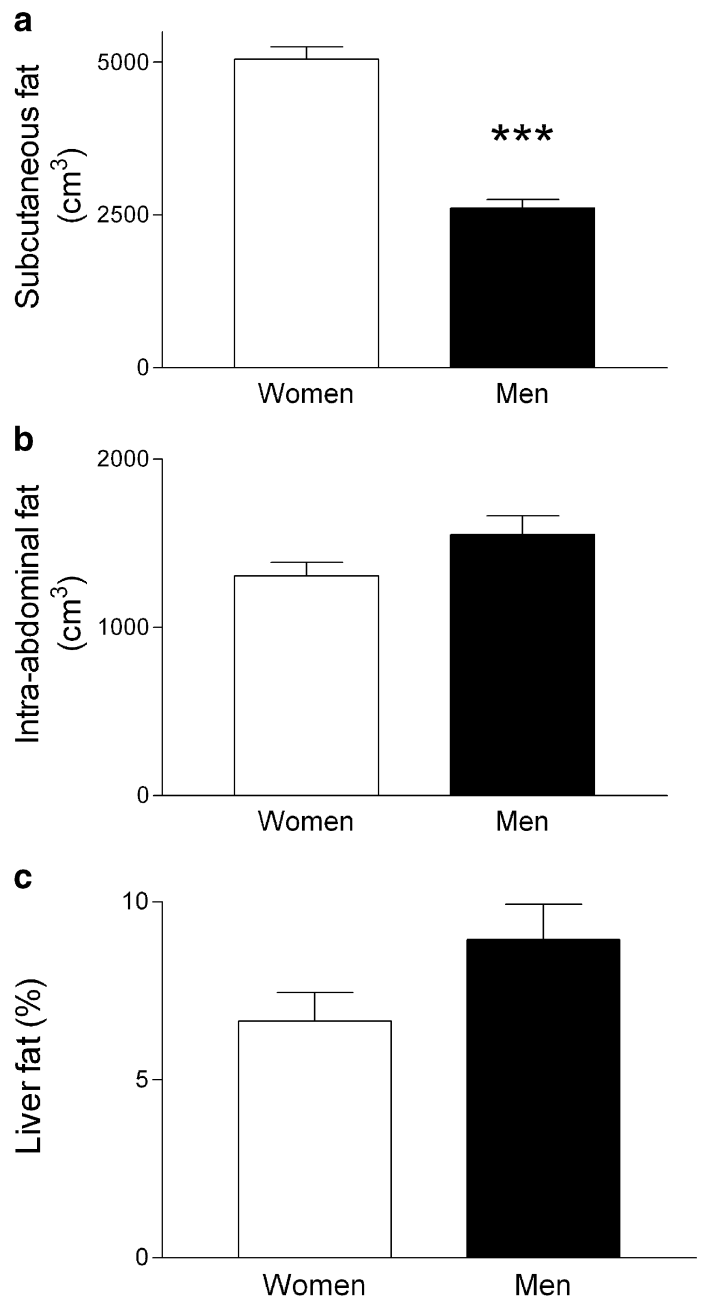

Fig. 1. Bar graphs show subcutaneous (a), intra-abdominal (b), and liver (c) fat content in women (white bars, $n=66$ ) and men (black bars, $n=66)$. Data are shown as means \pm SEM. *** $p<0.001$ vs women

intercepts differed between women and men, a common regression equation was calculated for all data. Regarding SNP276 genotypes, continuous variables were compared between genotype groups by ANOVA. All analyses were adjusted for age and sex. Multiple linear regression analysis was used to search for independent causes of variation in liver fat content and serum fasting insulin concentrations. Calculations were made using GraphPad Prism version 3.00 for Windows (GraphPad Software, San Diego, Calif., USA) and SPSS 11.0 for Windows (SPSS, Chicago, Ill., USA). Data are shown as means \pm SEM. A $p$ value of less than 0.05 was considered statistically significant.

\section{Results}

The women and men were similar with respect to age and absolute body weight (Table 1). The women were more obese than the men, as judged from their BMI and percentage body fat. This was due to an almost two-fold larger volume of subcutaneous fat in the women compared with in the men (Fig. 1). Despite
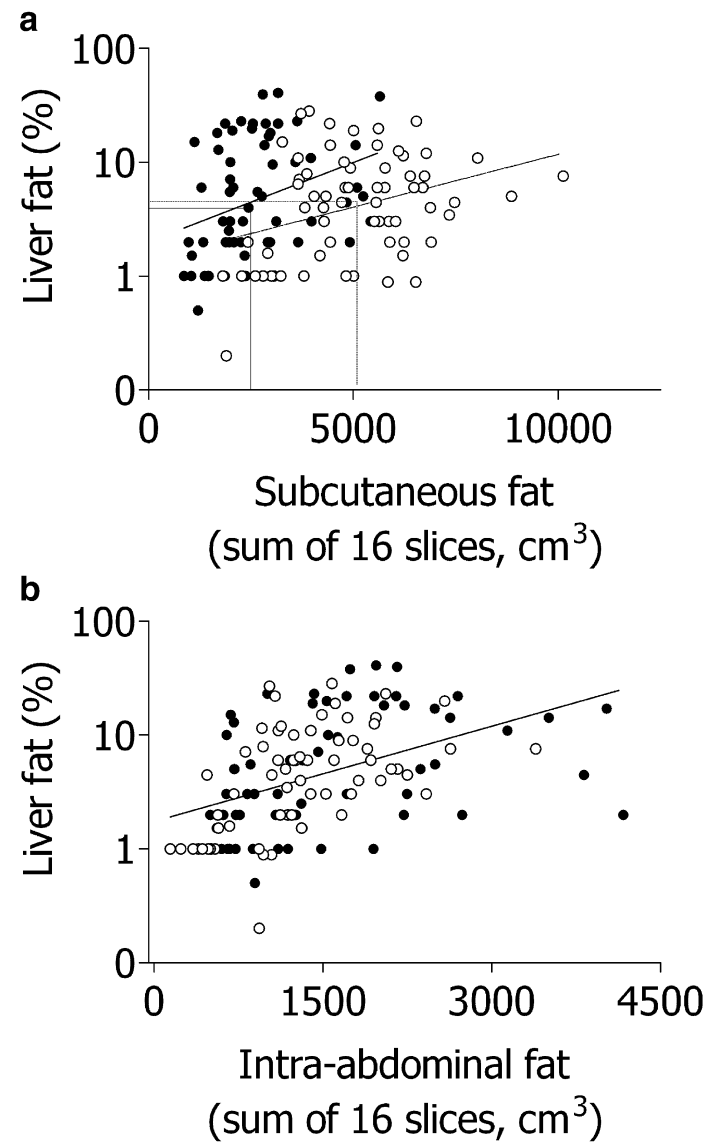

Fig. 2a. The relationships between subcutaneous fat (assessed using magnetic resonance imaging) and liver fat (measured using proton spectroscopy) in 66 women (open circles, hatched line, $r=0.33, p=0.007$ ) and 66 men (closed circles, solid line, $r=0.32, p=0.010$ ). The additional lines indicate mean values for subcutaneous fat in women (hatched line) and men (solid line) and the corresponding mean liver fat content. b. The relationship between intra-abdominal fat and liver fat $(r=0.45$, $p<0.0001)$ for pooled values in men (closed circles) and women (open circles)

this difference, intra-abdominal fat and liver fat contents were similar in women and men (Fig. 1). The ratio of liver fat content : subcutaneous fat volume averaged $1.4 \pm 0.2 \% / \mathrm{dm}^{3}$ in women and $3.5 \pm 0.5 \% / \mathrm{dm}^{3}$ in men $(p<0.001)$. Markers of insulin resistance, including serum fasting insulin, C-peptide, triglyceride and HDL cholesterol concentrations, were also similar in both groups (Table 1). Serum ALT was significantly lower in women than in men $(35 \pm 4$ vs $53 \pm 8 \mathrm{U} / \mathrm{l}$, $p<0.05)$, whereas the two groups had similar concentrations of serum AST ( $32 \pm 3$ vs $35 \pm 3 \mathrm{U} / \mathrm{l}, \mathrm{NS})$ and GGT $(38 \pm 5$ vs $41 \pm 4$ U/l, NS).

Interrelationships between measures of body composition and liver fat in women and men. The volume of subcutaneous fat was positively correlated with liver fat in both women and men, but for any given liver fat content, women had almost two-fold more subcutaneous fat than men (Fig. 2). Intra-abdominal fat was also positively correlated with liver fat, but in this case 


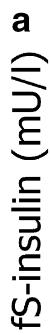
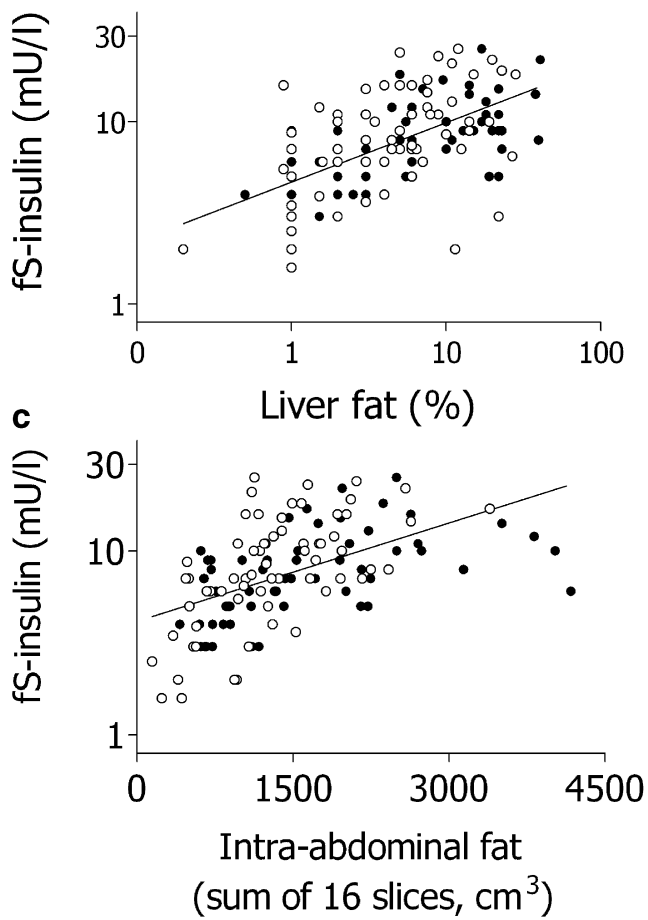

Fig. 3. The relationships between (a) liver fat and fasting serum insulin $(r=0.58, p<0.0001)$, (b) liver fat and fasting serum triglycerides $(r=0.38, p<0.0001)$ and $(\mathbf{c})$ intra-abdominal fat and fasting serum insulin $(r=0.52, p<0.0001)$ for pooled values in men (closed circles) and women (open circles). d. The relationship between subcutaneous fat and fasting serum insulin in 66 women (open circles, hatched line, $r=0.56, p<0.0001$ ) and 66 men (closed circles, solid line, $r=0.52, p<0.0001$ ). The additional lines denote mean values for subcutaneous fat in women (hatched line) and men (solid line) and the corresponding mean serum insulin concentration

values for the different sexes fell on the same regression line (Fig. 2).

Interrelationships between liver fat and features of insulin resistance in women and men. Liver fat was closely correlated with serum insulin (Fig. 3) and Cpeptide (data not shown, pooled value for women and men $r=0.41, p<0.001)$ in both women and men, with no sex differences observed between the slopes or intercepts relating these parameters. Intra-abdominal fat was similarly correlated with serum insulin in women and men (Fig. 3); conversely, subcutaneous fat was not. Sex did not affect the relationship between liver fat and serum triglycerides (Fig. 3) or HDL cholesterol (data not shown, pooled value for women and men $r=-0.41, p<0.001)$.

Serum ALT as a marker of liver fat in women and men. Serum ALT was positively correlated with liver fat in both women and men, but for a given percentage of liver fat, serum ALT was lower in women than in men (Fig. 4). There was no difference between the
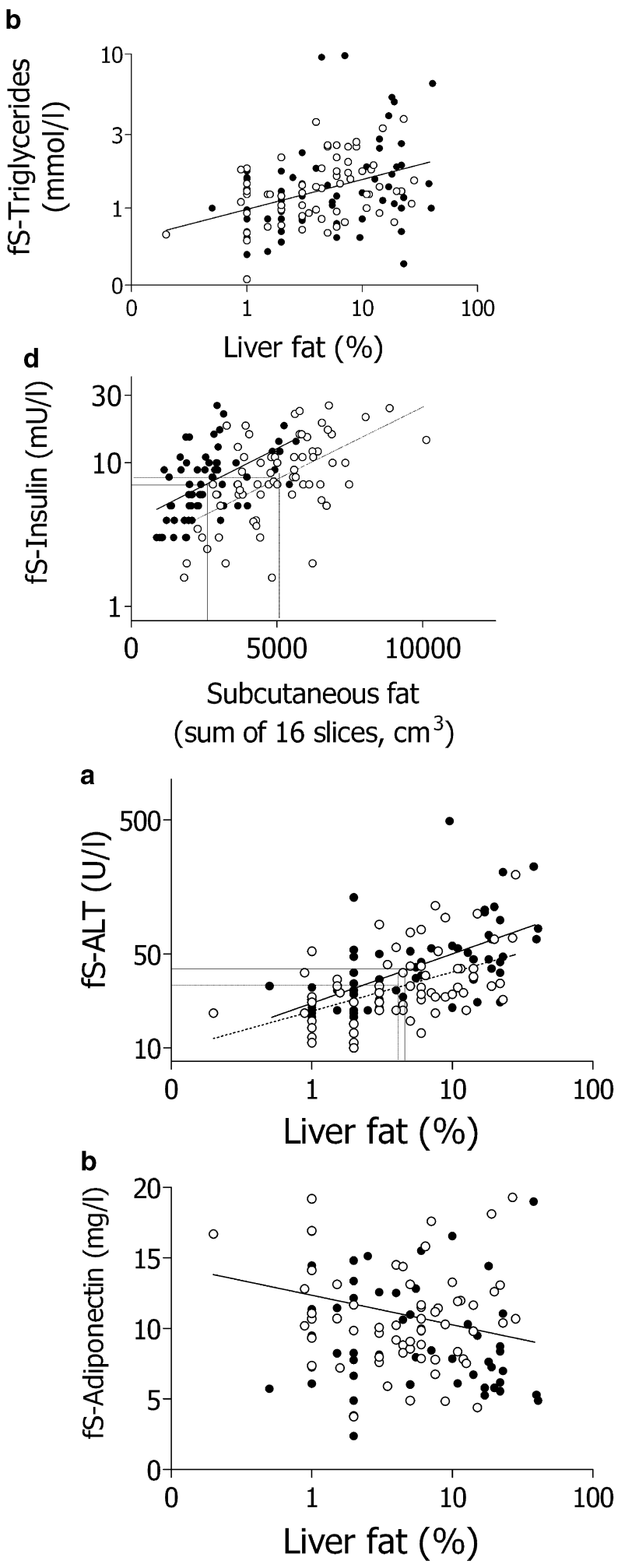

Fig. 4a. The relationship between liver fat and serum ALT in 66 women (open circles, hatched line, $r=0.49, p<0.0001$ ) and 66 men (closed circles, solid line, $r=0.62, p<0.0001$ ). The additional lines denote mean values for liver fat in women (hatched line) and men (solid line) and the corresponding serum ALT. b. The relationship between liver fat and serum adiponectin $(r=-0.21, p=0.019)$ for pooled values in men (closed circles) and women (open circles). ALT, alanine aminotransferase 
Table 2. Multivariate regression models searching for independent correlates of liver fat content and fasting serum insulin

\begin{tabular}{|c|c|c|c|}
\hline \multicolumn{4}{|c|}{ Liver fat $(\%)^{*}(r=0.429, p<0.001)$} \\
\hline Effect & Regression & Standardised error & $p$ value \\
\hline Constant & -0.141 & 0.265 & 0.595 \\
\hline Intra-abdominal fat $\left(\mathrm{cm}^{3}\right)$ & $2.157 \times 10^{-4}$ & 0.000 & $<0.001$ \\
\hline Adiponectin (mg/l) & -0.296 & 0.228 & 0.197 \\
\hline \multicolumn{4}{|c|}{ Serum insulin $(\mathrm{mU} / \mathrm{l}) * *(r=0.422, p<0.001)$} \\
\hline Liver fat $(\%)$ & 0.150 & 0.040 & $<0.001$ \\
\hline Adiponectin (mg/l) & -0.258 & 0.093 & 0.006 \\
\hline Intra-abdominal fat $\left(\mathrm{cm}^{3}\right)$ & $-2.926 \times 10^{-5}$ & 0.000 & 0.239 \\
\hline Subcutaneous fat $\left(\mathrm{cm}^{3}\right)$ & $-4.507 \times 10^{-6}$ & 0.000 & 0.633 \\
\hline
\end{tabular}

* Adjusted for age and sex; ** adjusted for age, sex and BMI

slopes of the regression lines relating liver fat to ALT in the two groups, but the $y$-intercept was significantly lower $(p=0.003)$ in women than in men. This difference is consistent with the lower reference range for serum ALT in women (10-40 U/l) compared with men $(10-50 \mathrm{U} / \mathrm{l})$ in our laboratory. At the upper limit of their respective reference range for serum ALT, liver fat averaged $13 \%$ in women and $10 \%$ in men. In total, $23 \%$ of the women and $29 \%$ of the men had serum ALT values higher than the upper limit of normal. The pooled male and female values for serum AST $(r=0.46, p<0.001)$ and GGT $(r=0.30, p<0.001)$ were correlated with liver fat.

Serum adiponectin and the SNP276 polymorphism of the adiponectin gene. Despite greater overall adiposity in the women compared with the men, serum adiponectin concentrations were similar in the two groups (Table 1). Serum adiponectin concentrations were inversely related to liver fat content (Fig. 4). This relationship was similar in women and men. The genotypic distribution of the SNP276 polymorphism was: $\mathrm{G} / \mathrm{G} 49 \%, \mathrm{G} / \mathrm{T} 42 \%, \mathrm{~T} / \mathrm{T} 9 \%$, to give an allelic distribution of $70 \%$ and $30 \%$ for the $\mathrm{G}$ and the $\mathrm{T}$ allele, respectively. Because heterozygotes and homozygotes for the minor allelles gave very similar results for every variable tested (data not shown), the values for the $\mathrm{G} / \mathrm{T}$ and $\mathrm{T} / \mathrm{T}$ genotypes were combined and compared with those for the $\mathrm{G} / \mathrm{G}$ genotype. Waist circumference $(p=0.066)$ and body weight $(p=0.084)$ were marginally significantly associated with the $\mathrm{G} / \mathrm{G}$ genotype. Conversely, serum adiponectin concentrations and liver fat were not associated with a particular genotype.

Independent correlates of liver fat and serum insulin. To determine independent correlates of liver fat, a multiple linear regression analysis was employed (Table 2). In a model including intra-abdominal and subcutaneous fat and serum adiponectin, intra-abdominal fat was the only independent correlate of liver fat adjusted for age and sex. In another model, liver fat and serum adiponectin were both significantly correlated with serum insulin, whereas intra-abdominal fat and subcutaneous fat volumes were not.

\section{Discussion}

To our knowledge, the present study is the largest to: (i) examine the relationships between liver fat and the size of other fat depots and features of insulin resistance; and (ii) investigate sex differences in these relationships. We found that, for equal amounts of liver fat, women and men had similar amounts of intra-abdominal fat, but women had almost twice as much subcutaneous fat as men. Of all fat depots, liver fat was best correlated with features of insulin resistance, such as serum insulin and triglycerides, and this association was independent of age, sex, BMI, and intraabdominal and subcutaneous fat. However, intra-abdominal fat was an independent determinant of liver fat content.

The women were matched to the men with respect to age and absolute body weight, but the women were clearly more (superficially) obese than the men were. One could question whether it is possible to compare sex differences in fat depots between such groups. It is clear that there was a large overlap between the groups for all parameters, and the essential findings were confirmed by simple and multiple linear regression analyses. As in previous studies, we found men to have a higher intra-abdominal fat : subcutaneous fat ratio than women $[31,32,33,34,35,36]$. Earlier studies have also identified close correlations between intra-abdominal fat and insulin sensitivity in both women $[37,38,39,40,41,42]$ and men $[37,38,40,41,43$, 44]. In studies comparing men and women [35, 37, $38,40,41]$, sex differences in lipoprotein levels [35, $37,38,41]$ and insulin [40] have either disappeared or 
have been greatly reduced after adjusting for visceral fat (either measured accurately by computed tomography [41] or estimated from waist-to-hip ratios [37, 38, 40]). Importantly, a large prospective study in Sweden demonstrated that men had a four-fold increased risk of CVD compared with women, which disappeared after adjustment of the figures for sex differences in the waist-to-hip ratio [45]. Our finding of similar regression lines between intra-abdominal fat, and serum insulin (Fig. 3) and triglyceride concentrations (data not shown) in men and women are consistent with these findings.

In multivariate analysis including liver fat, the associations between serum fasting insulin (adjusted for age, sex and BMI) and intra-abdominal and subcutaneous fat volumes disappeared, suggesting that fat accumulation in the liver is the most proximal correlate of insulin resistance. Liver fat content correlated significantly with fasting insulin and C-peptide concentrations, with no difference observed between women and men. No other studies investigating correlations between features of insulin resistance and liver fat have included both male and female non-diabetic subjects. However, previous smaller studies have shown relationships between liver fat and features of insulin resistance in patients with Type 2 diabetes $[46,47]$ in Japanese [48] and Caucasian men [2, 3, 16] and in obese women with previous gestational diabetes [17]. The present study is limited by the fact that serum fasting insulin was used as a measure of insulin sensitivity rather than directly measured hepatic insulin sensitivity. However, in a previous study of healthy, middle-aged subjects, the correlation (unpublished data in reference [16]) between fasting insulin and liver fat was stronger than that between hepatic insulin sensitivity and liver fat, possibly for methodological reasons.

The finding that liver fat was a significant independent correlate of insulin resistance, whereas intra-abdominal fat was not, does not mean that intra-abdominal fat is not an important determinant of liver fat. Indeed, multivariate analysis revealed that intra-abdominal fat was the only significant independent correlate of this fat depot. One mechanism by which intra-abdominal fat could regulate liver fat content is through the release of NEFA into the portal vein. However, catheterisation studies have suggested that fatty acids released by the splanchnic bed constitute only $\sim 10 \%$ of the total amount of NEFA delivered to the liver [49]. Other, similar studies have indicated that the increased delivery of NEFA to the liver in individuals with an abdominal type of fat distribution is due to the excessive release of NEFA by upper body subcutaneous adipose tissue as opposed to visceral adipose tissue $[50,51]$. Another possibility is that mediators other than NEFA are involved. In humans, visceral fat expresses higher levels of IL-6 [52], angiotensinogen [53, 54], complement components [54, 55], cellular inhibitor of apoptosis protein-2 [56, 57] and glucocorticoid receptors [58] than subcutaneous adipose tissue does.

Although intra-abdominal fat was independently correlated with liver fat, the lack of an independent relationship between intra-abdominal fat and fasting insulin when liver fat was included in the multivariate analysis suggests that factors other than intra-abdominal fat influence liver fat content. One possibility is that dietary fat content or composition contributes to liver fat. The fatty acids could be those released by lipoprotein lipase that are not taken up by skeletal muscle or adipose tissue [59], or they may be contained in chylomicron remnants, which are taken up directly by the liver. It is estimated that up to $50 \%$ of dietary fat is taken up as remnant triglyceride by the liver [60]. Although dietary intake was not quantified in the present study, we have previously found a correlation between the percentage saturated fat in the diet and liver fat content [61]. Feeding rabbits a high-fat diet results in rapid fat accumulation in the liver [62]. Although individuals consuming more than moderate amounts of alcohol were excluded from the present study, it is also possible that alcohol intake contributed to liver fat content. In a recent analysis of data on adults aged 17 years and older $(n=15,676)$ from the Third National Health and Nutrition Examination Survey, aminotransferase concentrations were linearly related to alcohol intake in both men and women, even in the range of between 0 and 2 drinks per day [1]. It is unclear whether steatosis caused by either alcohol intake or by unexplained reasons (i.e. by NAFLD) is associated with insulin resistance. Histologically, macrovesicular steatosis induced by alcohol is indistinguishable from that associated with insulin resistance [63].

Adiponectin deficiency correlated with increased liver fat. Since adiponectin deficiency and increased liver fat content characterises both those individuals with excess fat $[64,65]$ and those with too little fat [66], adiponectin deficiency could be the critical factor regulating liver fat content rather than the amount of subcutaneous fat. Adiponectin has recently been shown to alleviate NAFLD in mice by increasing carnitine palmitoyltransferase- 1 activity and hepatic fat oxidation, and by suppressing TNF- $\alpha$ production in the liver and in plasma [67]. In mice, adiponectin suppresses hepatic glucose production $[68,69]$ via activation of adenosine monophosphate-activated protein kinase in the liver [70]. Adiponectin concentrations have previously been found to be higher in women than in men who are matched in terms of relative body weight [71]. The present finding of similar adiponectin concentrations in men and women, despite the fact that the women were more obese than the men, is in keeping with such data. Given that adiponectin concentrations and liver fat contents were similar in the two groups, and that the two parameters 
were interrelated, it is possible that adiponectin contributed to liver fat in the present study. Conversely, it is important to emphasise that the cross-sectional design of the present study does not allow us to deduce cause-effect relationships. Regarding genetic variation in the adiponectin gene, four rare mutations and two frequent polymorphisms have been described as associated with metabolic alterations such as body weight [20], insulin resistance [20] and Type 2 diabetes $[21,72]$. Previous studies have found the $G / G$ genotype at position 276 in the adiponectin gene to be associated with an increased risk of Type 2 diabetes in Japanese subjects [21], and with body weight but not Type 2 diabetes in Caucasians [20]. In the present study, the frequency of the $G / G$ genotype $(49 \%)$ was very similar to that reported in the two other studies. After adjusting for age and sex, we found that waist circumference $(p=0.066)$ and body weight $(p=0.084)$ were marginally significantly associated with the $G / G$ genotype, whereas, in contrast with other studies, adiponectin concentration was not [20]. These data support the previous data, although the other reports $[20,21,72]$ included three to four times as many subjects as the present study.

Serum ALT was significantly correlated with percentage liver fat, as measured using proton spectroscopy. While the slopes of the plots of these relationships were similar in the two groups, mean serum ALT values were lower in women than in men. This observation is consistent with the lower reference range for serum ALT in women compared with that in men, that may be due to their relatively smaller liver volume. Although the correlations between liver fat and serum ALT were not perfect, they nevertheless suggest that serum ALT might be a useful marker of liver fat, and in individuals lacking other causes of liver damage, of insulin resistance. We have previously shown liver fat content to be significantly correlated with insulin requirements in patients with Type 2 diabetes [23], and others have shown serum ALT to predict Type 2 diabetes [14] and CVD (West of Scotland Coronary Prevention Study data, unpublished).

In summary, the present data suggest that liver fat is a more proximal correlate of insulin resistance than intra-abdominal fat, which in turn appears to be a determining factor of liver fat content. In contrast to subcutaneous fat, the relationships between intra-abdominal fat and: (i) liver fat; and (ii) features of insulin resistance are similar in men and women.

Acknowledgements. The study was supported by grants from the Academy of Finland and the Sigrid Juselius Foundation. We gratefully acknowledge P. Pölönen, K. Tuominen, M. Toivonen and V. Naatti for excellent technical assistance.

\section{References}

1. Clark JM, Brancati FL, Diehl AM (2003) The prevalence and etiology of elevated aminotransferase levels in the United States. Am J Gastroenterol 98:960-967

2. Marceau P, Biron S, Hould FS et al. (1999) Liver pathology and the metabolic syndrome $\mathrm{X}$ in severe obesity. J Clin Endocrinol Metab 84:1513-1517

3. Marchesini G, Brizi M, Bianchi G et al. (2001) Nonalcoholic fatty liver disease: a feature of the metabolic syndrome. Diabetes 50:1844-1850

4. Hartz AJ, Rupley DC, Rimm AA (1984) The association of girth measurements with disease in 32,856 women. Am J Epidemiol 119:71-80

5. Landin K, Stigendal L, Eriksson E et al. (1990) Abdominal obesity is associated with an impaired fibrinolytic activity and elevated plasminogen activator inhibitor-1. Metabolism 39:1044-1048

6. Katzel LI, Busby-Whitehead MJ, Goldberg AP (1993) Adverse effects of abdominal obesity on lipoprotein lipids in healthy older men. Exp Gerontol 28:411-420

7. Ohlson L-O, Larsson B, Svärdsudd K et al. (1985) The influence of body fat distribution on the incidence of diabetes mellitus. 13.5 years of follow-up of the participants in the study of men in 1913. Diabetes 34:1055-1058

8. Kaye SA, Folsom AR, Sprafka JM, Prineas RJ, Wallace RB (1991) Increased incidence of diabetes mellitus in relation to abdominal adiposity in older women. J Clin Epidemiol 44:329-334

9. Casassus P, Fontbonne A, Thibult N et al. (1992) Upperbody fat distribution: a hyperinsulinemia-independent predictor of coronary heart disease mortality. The Paris Prospective Study. Arterioscler Thromb 12:1387-1392

10. Frayn KN (2000) Visceral fat and insulin resistance-causative or correlative? Br J Nutr 83 [Suppl 1]:S71-S77

11. Reitman ML, Arioglu E, Gavrilova O, Taylor SI (2000) Lipoatrophy revisited. Trends Endocrinol Metab 11:410-416

12. Kim JK, Gavrilova O, Chen Y, Reitman ML, Shulman GI (2000) Mechanism of insulin resistance in A-ZIP/F-1 fatless mice. J Biol Chem 275:8456-8460

13. Gavrilova O, Marcus-Samuels B, Graham D et al. (2000) Surgical implantation of adipose tissue reverses diabetes in lipoatrophic mice. J Clin Invest 105:271-278

14. Vozarova B, Stefan N, Lindsay RS et al. (2002) High alanine aminotransferase is associated with decreased hepatic insulin sensitivity and predicts the development of type 2 diabetes. Diabetes 51:1889-1895

15. Sutinen J, Häkkinen AM, Westerbacka J et al. (2002) Increased fat accumulation in the liver in HIV-infected patients with antiretroviral therapy-associated lipodystrophy. AIDS 16:2183-2193

16. Seppälä-Lindroos A, Vehkavaara S, Häkkinen AM et al. (2002) Fat accumulation in the liver is associated with defects in insulin suppression of glucose production and serum free fatty acids independent of obesity in normal men. J Clin Endocrinol Metab 87:3023-3028

17. Tiikkainen M, Tamminen M, Häkkinen AM et al. (2002) Liver-fat accumulation and insulin resistance in obese women with previous gestational diabetes. Obes Res 10:859-867

18. Yamauchi T, Kamon J, Waki H et al. (2001) The fat-derived hormone adiponectin reverses insulin resistance associated with both lipoatrophy and obesity. Nat Med 7:941-946

19. Yu JG, Javorschi S, Hevener AL et al. (2002) The effect of thiazolidinediones on plasma adiponectin levels in normal, obese, and type 2 diabetic subjects. Diabetes 51:2968-2974

20. Menzaghi C, Ercolino T, Di Paola R et al. (2002) A haplotype at the adiponectin locus is associated with obesity and 
other features of the insulin resistance syndrome. Diabetes 51:2306-2312

21. Hara K, Boutin P, Mori Y et al. (2002) Genetic variation in the gene encoding adiponectin is associated with an increased risk of type 2 diabetes in the Japanese population. Diabetes 51:536-540

22. Thomsen C, Becker U, Winkler K, Christoffersen P, Jensen M, Henriksen O (1994) Quantification of liver fat using magnetic resonance spectroscopy. Magn Reson Imaging 12:487-495

23. Ryysy L, Häkkinen AM, Goto T et al. (2000) Hepatic fat content and insulin action on free fatty acids and glucose metabolism rather than insulin absorption are associated with insulin requirements during insulin therapy in type 2 diabetic patients. Diabetes 49:749-758

24. Lukaski HC, Johnson PE, Bolonchuk WW, Lykken GI (1985) Assessment of fat-free mass using bioelectrical impedance measurements of the human body. Am J Clin Nutr 41:810-817

25. Marti B, Tuomilehto J, Salomaa V, Kartovaara L, Korhonen HJ, Pietinen P (1991) Body fat distribution in the Finnish population: environmental determinants and predictive power for cardiovascular risk factor levels. J Epidemiol Community Health 45:131-137

26. Kadish AH, Little RL, Sternberg JC (1968) A new and rapid method for the determination of glucose by measurement of rate of oxygen consumption. Clin Chem 14:116-131

27. Kuzuya H, Blix PM, Horwitz DL, Steiner DF, Rubenstein AH (1977) Determination of free and total insulin and Cpeptide in insulin-treated diabetics. Diabetes 26:22-29

28. Stenman U-H, Pesonen K, Ylinen K, Huhtala ML, Teramo K (1984) Rapid chromatographic quantitation of glycosylated haemoglobins. J Chromatogr 297:327-332

29. Friedewald WT, Levy RI, Fredrickson DS (1972) Estimation of the concentration of low-density lipoprotein cholesterol in plasma, without use of the preparative ultracentrifuge. Clin Chem 18:499-502

30. Wonnacott TH, Wonnacott RJ (1977) Tests for randomness-Runs test. In: Wonnacott TH, Wonnacott RJ (eds) Introductory statistics. Wiley, New York, pp 486-488

31. Vague J (1956) The degree of masculine differentiation of obesities: a factor determining predisposition to diabetes, atherosclerosis, gout, and uric calculous disease. Am J Clin Nutr 4:20-34

32. Enzi G, Gasparo M, Biondetti PR, Fiore D, Semisa M, Zurlo F (1986) Subcutaneous and visceral fat distribution according to sex, age, and overweight, evaluated by computed tomography. Am J Clin Nutr 44:739-746

33. Schreiner PJ, Terry JG, Evans GW, Hinson WH, Crouse JR, Heiss G (1996) Sex-specific associations of magnetic resonance imaging-derived intra-abdominal and subcutaneous fat areas with conventional anthropometric indices. The Atherosclerosis Risk in Communities Study. Am J Epidemiol 144:335-345

34. Cnop M, Landchild MJ, Vidal J et al. (2002) The concurrent accumulation of intra-abdominal and subcutaneous fat explains the association between insulin resistance and plasma leptin concentrations: distinct metabolic effects of two fat compartments. Diabetes 51:1005-1015

35. Bertrais S, Balkau B, Vol S et al. (1999) Relationships between abdominal body fat distribution and cardiovascular risk factors: an explanation for women's healthier cardiovascular risk profile. The D.E.S.I.R. Study. Int J Obes Relat Metab Disord 23:1085-1094

36. Grauer WO, Moss AA, Cann CE, Goldberg HI (1984) Quantification of body fat distribution in the abdomen using computed tomography. Am J Clin Nutr 39:631-637
37. Freedman DS, Jacobsen SJ, Barboriak JJ et al. (1990) Body fat distribution and male/female differences in lipids and lipoproteins. Circulation 81:1498-1506

38. Lyu LC, Shieh MJ, Bailey SM et al. (1994) Relationship of body fat distribution with cardiovascular risk factors in healthy Chinese. Ann Epidemiol 4:434-444

39. Carey DG, Jenkins AB, Campbell LV, Freund J, Chisholm DJ (1996) Abdominal fat and insulin resistance in normal and overweight women: Direct measurements reveal a strong relationship in subjects at both low and high risk of NIDDM. Diabetes 45:633-638

40. Colman E, Toth MJ, Katzel LI, Fonong T, Gardner AW, Poehlman ET (1995) Body fatness and waist circumference are independent predictors of the age-associated increase in fasting insulin levels in healthy men and women. Int $\mathbf{J}$ Obes Relat Metab Disord 19:798-803

41. Lemieux S, Despres JP, Moorjani S et al. (1994) Are gender differences in cardiovascular disease risk factors explained by the level of visceral adipose tissue? Diabetologia 37:757-764

42. Pouliot MC, Despres JP, Lemieux S et al. (1994) Waist circumference and abdominal sagittal diameter: best simple anthropometric indexes of abdominal visceral adipose tissue accumulation and related cardiovascular risk in men and women. Am J Cardiol 73:460-468

43. Ross R, Aru J, Freeman J, Hudson R, Janssen I (2002) Abdominal adiposity and insulin resistance in obese men. Am J Physiol Endocrinol Metab 282:E657-E663

44. Nguyen-Duy TB, Nichaman MZ, Church TS, Blair SN, Ross R (2003) Visceral fat and liver fat are independent predictors of metabolic risk factors in men. Am J Physiol Endocrinol Metab 284:E1065-E1071

45. Larsson B, Bengtsson C, Bjorntorp P et al. (1992) Is abdominal body fat distribution a major explanation for the sex difference in the incidence of myocardial infarction? The study of men born in 1913 and the study of women, Goteborg, Sweden. Am J Epidemiol 135:266-273

46. Banerji MA, Buckley MC, Chaiken RL, Gordon D, Lebovitz HE, Kral JG (1995) Liver fat, serum triglycerides and visceral adipose tissue in insulin-sensitive and insulinresistant black men with NIDDM. Int J Obes Relat Metab Disord 19:846-850

47. Kelley DE, McKolanis TM, Hegazi RA, Kuller LH, Kalhan SC (2003) Fatty liver in type 2 diabetes mellitus: relation to regional adiposity, fatty acids, and insulin resistance. Am J Physiol Endocrinol Metab 285:E906-E916

48. Goto T, Onuma T, Takebe K, Kral JG (1995) The influence of fatty liver on insulin clearance and insulin resistance in non-diabetic Japanese subjects. Int J Obes Relat Metab Disord 19:841-845

49. Havel RJ, Kane JP, Balasse EO, Segel N, Basso LV (1970) Splanchnic metabolism of free fatty acids and production of triglycerides of very low density lipoproteins in normotriglyceridemic and hypertriglyceridemic humans. J Clin Invest 49:2017-2035

50. Martin ML, Jensen MD (1991) Effects of body fat distribution on regional lipolysis in obesity. J Clin Invest 88: 609-613

51. Guo Z, Hensrud DD, Johnson CM, Jensen MD (1999) Regional postprandial fatty acid metabolism in different obesity phenotypes. Diabetes 48:1586-1592

52. Fried SK, Bunkin DA, Greenberg AS (1998) Omental and subcutaneous adipose tissues of obese subjects release interleukin-6: depot difference and regulation by glucocorticoid. J Clin Endocrinol Metab 83:847-850

53. Van HV, Elizalde M, Ariapart P et al. (2000) The association of human adipose angiotensinogen gene expression 
with abdominal fat distribution in obesity. Int J Obes Relat Metab Disord 24:673-678

54. Dusserre E, Moulin P, Vidal H (2000) Differences in mRNA expression of the proteins secreted by the adipocytes in human subcutaneous and visceral adipose tissues. Biochim Biophys Acta 1500:88-96

55. Gabrielsson BG, Johansson JM, Lonn M et al. (2003) High expression of complement components in omental adipose tissue in obese men. Obes Res 11:699-708

56. Montague CT, Prins JB, Sanders L et al. (1998) Depot-related gene expression in human subcutaneous and omental adipocytes. Diabetes 47:1384-1391

57. Niesler CU, Prins JB, O'Rahilly S, Siddle K, Montague CT (2001) Adipose depot-specific expression of cIAP2 in human preadipocytes and modulation of expression by serum factors and TNF- $\alpha$. Int J Obes Relat Metab Disord 25:1027-1033

58. Rebuffe-Scrive M, Bronnegard M, Nilsson A, Eldh J, Gustafsson JA, Bjorntorp P (1990) Steroid hormone receptors in human adipose tissues. J Clin Endocrinol Metab 71:1215-1219

59. Evans K, Burdge GC, Wootton SA, Clark ML, Frayn KN (2002) Regulation of dietary fatty acid entrapment in subcutaneous adipose tissue and skeletal muscle. Diabetes 51:2684-2690

60. Hultin M, Savonen R, Olivecrona T (1996) Chylomicron metabolism in rats: lipolysis, recirculation of triglyceridederived fatty acids in plasma FFA, and fate of core lipids as analyzed by compartmental modelling. J Lipid Res 37:1022-1036

61. Tiikkainen M, Bergholm R, Vehkavaara S et al. (2003) Effects of identical weight loss on body composition and features of insulin resistance in obese women with high and low liver fat content. Diabetes 52:701-707

62. Duee PH, Pegorier JP, el Manoubi L, Herbin C, Kohl C, Girard J (1985) Hepatic triglyceride hydrolysis and development of ketogenesis in rabbits. Am J Physiol 249:E478-E484
63. Reid AE (2001) Nonalcoholic steatohepatitis. Gastroenterology 121:710-723

64. Arita Y, Kihara S, Ouchi N et al. (1999) Paradoxical decrease of an adipose-specific protein, adiponectin, in obesity. Biochem Biophys Res Commun 257:79-83

65. Weyer C, Funahashi T, Tanaka S et al. (2001) Hypoadiponectinemia in obesity and type 2 diabetes: close association with insulin resistance and hyperinsulinemia. J Clin Endocrinol Metab 86:1930-1935

66. Sutinen J, Korsheninnikova E, Funahashi T, Matsuzawa Y, Nyman T, Yki-Jarvinen H (2003) Circulating concentration of adiponectin and its expression in subcutaneous adipose tissue in patients with highly active antiretroviral therapyassociated lipodystrophy. J Clin Endocrinol Metab 88:1907-1910

67. Xu A, Wang Y, Keshaw H, Xu LY, Lam KS, Cooper GJ (2003) The fat-derived hormone adiponectin alleviates alcoholic and nonalcoholic fatty liver diseases in mice. J Clin Invest 112:91-100

68. Berg AH, Combs TP, Du X, Brownlee M, Scherer PE (2001) The adipocyte-secreted protein Acrp30 enhances hepatic insulin action. Nat Med 7:947-953

69. Combs TP, Berg AH, Obici S, Scherer PE, Rossetti L (2001) Endogenous glucose production is inhibited by the adiposederived protein Acrp30. J Clin Invest 108:1875-1881

70. Yamauchi T, Kamon J, Minokoshi Y et al. (2002) Adiponectin stimulates glucose utilization and fatty-acid oxidation by activating AMP-activated protein kinase. Nat Med 8:1288-1295

71. Shand BI, Scott RS, Elder PA, George PM (2003) Plasma adiponectin in overweight, nondiabetic individuals with or without insulin resistance. Diabetes Obes Metab 5:349-353

72. Waki H, Yamauchi T, Kamon J et al. (2003) Impaired multimerization of human adiponectin mutants associated with diabetes: molecular structure and multimer formation of adiponectin. J Biol Chem 278:40352-40363 